\title{
nature
}

\section{Benefits of increased public participation}

US research, industries and citizens have something to gain from European experiments in public participation in regulation. So do those in Europe.

t would be absurd to suggest that science can be conducted democratically. It would be no less ridiculous to suggest that consideration of the impact of science and the regulation of its applications should be left entirely to the discretion of scientists and those who fund or employ them. But few governments of scientifically developed countries are sufficiently aware of the public's significant interest (in both senses of that word) in research to respond with the required commitment and resources.

It can be useful to distinguish, somewhat artificially, between active stakeholders associated with a particular issue and concerned publics. Stakeholders may include industrialists, investors in the stock market, food retailers, doctors, government ministries, farmers, lawyers, learned societies, publishers, the media, anti-biotech and green lobbyists, and disease sufferers' organizations. Publics have no immediate stake in the issue, but know that it will have an impact on the society in which they live and would willingly grasp an opportunity to have a voice.

\section{Stronger foundations}

A greater effort spent in giving non-stakeholder publics a voice and a demonstrable influence on the regulation of science and technology would leave scientific research, and industries built on it, in a healthier state. Not because society will necessarily be more accepting of a particular development as a result, nor because the public will necessarily be more scientifically educated; by virtue, rather, of the greater extent to which irrationality or vested interests can be countered and a foundation of greater public confidence and mutual trust established. Above all, the goal should be to build greater anticipation of progress and a stronger foundation for public consideration of, and beyond, the science. There is a prospect then that public discussion and regulation could be that much less likely to be held hostage to the interests of those who shout both loudly and misleadingly or those who wield disproportionate influence behind the scenes.

An inevitable objection to such a move is that the public lack the education and knowledge to assess science. In some complex topics this is a justified concern. But many scientists and industrialists who have been involved in public participatory events such as consensus conferences, or in the public consultative process recently established at the US National Institutes of Health, remark on the (to them) unexpected way in which the public representatives have little difficulty in absorbing key aspects of science in the discussion of ethical or human issues. They also welcome the ability of such lay panels, given the power to run the process and select their own witnesses, to penetrate screens of rhetoric and selective evidence.

Although some of its key decisions on regulation involving, for example, the Food and Drug Administration have been made too discreetly, the United States leads the world in providing information to the public on the web, and the extent to which it invites stakeholder consultation. A 1997 presidential commission on environmental-risk management made much of the way information to and consultation of stakeholders had led to examples of good development while a lack of them had resulted in decisions that foundered.

But organizations in the United States can enhance their considerations of science's impact by a more systematic involvement of the public. Much of the development of techniques for public participation has occurred in Europe (for an overview of those techniques and examples around the world see www.oecd.org/dsti/sti/s_t/biotech/ act/consultations.htm, and also the October 1999 special issue of Science and Public Policy). The pioneers of public participation have been the Danish Board of Technology, which has organized consensus conferences and scenario workshops for many years. The purpose of the board (see http://www.tekno.dk/eng/index.htm) is to help the Danish parliament be aware of the full range of issues associated with a particular technological development. The lay panel is briefed on those issues and, over a four-day period, can question anybody it wishes from research, industry and lobby groups about the issues, and writes a report (GM crops is one recent example) which is made freely available on the web. This panel represents the public interest in a way that stakeholders do not. The achievement of a consensus ensures at least that they have had to think through the issues in the required depth from a practical point of view.

The applicability of this model to other countries has been questioned on the grounds that, like the Netherlands, Denmark has a political culture that is unusually consensual. But that misses the point, which is that these conferences are not intended to reach policy decisions, and need not be applied at a national level. They are intended to shed light on citizens' concerns about key aspects of science and of issues surrounding it. To enlarge its consideration so as to include the wider public view, organizations in the United States would do well to build on such techniques.

\section{New resources}

Europe, too, should do more. In the United Kingdom there is a new set of bodies well placed, in principle, to incorporate such techniques into their formal responsibilities - the Human Genetics Commission, the Agriculture and Environment Biotechnology Commission and the Food Standards Agency. They have yet to prove themselves, and in their make-up are more detached from the interests of research and industry than were their predecessors. They should be given resources not only to provide high-quality and prompt contextual information for the media and the public, but also to develop public participatory studies of potentially contentious issues. Other countries in Europe - France and Germany — have a similar need, but show less readiness to move in this direction.

If they and the United States can draw more on the detached judgement of such panels, the process by which science can benefit society should improve. There is a need to adopt a more inclusive approach in grappling with the implications of increased scientific knowledge. Given what is sometimes at stake for economies and for citizens, there is no good excuse for not doing so. 